\title{
Gynaecology - Quo vadis? Situation Analysis, National and International Perspectives
}

\author{
Frauenheilkunde - quo vadis? Situationsanalyse, \\ nationale und internationale Perspektiven
}

Authors

Affiliations
S. Y. Brucker ${ }^{1,2,3 *}$, E. Simoes ${ }^{1,3 *}$, D. Wallwiener ${ }^{1,2}$

${ }^{1}$ Department for Women's Health, Tübingen

${ }^{2}$ University Women Hospital, Tübingen

${ }^{3}$ Women's Health Research Institute, Tübingen
Key words

- gynaecology

- health-care structures

- women's health

- department

Schlüsselwörter

- Gynäkologie

- Versorgungsstruktur

- Frauengesundheit

- Department

Deutschsprachige Zusatzinformationen online abrufbar unter: www.thieme-connect.de/ ejournals/toc/gebfra

\section{received 28.8.2014 \\ revised 20.10.2014 \\ accepted 21.10.2014}

\section{Bibliography}

DOI http://dx.doi.org/

10.1055/s-0034-1383383

Geburtsh Frauenheilk 2014; 74

1119-1127 @ Georg Thieme

Verlag KG Stuttgart · New York ISSN 0016-5751

\section{Correspondence}

Prof. Dr. med. Elisabeth Simoes

Department of Women's Health

University Hospital Tübingen

Women's Health Research

Institute

Calwer Straße 7

72076 Tübingen

elisabeth.simoes@

med.uni-tuebingen.de

\section{Abstract \\ $\nabla$}

In a large and heavily networked specialty like gynaecology it is a particular challenge with regard to future status to achieve excellent patient care, research and teaching. At the same time not only hospitals but also research facilities are experiencing increasing pressure from performance and competition sides in terms of survival and further development on the clinical, scientific and economic fronts. The numerous changes, including paradigm shifts, in medicine, society, the health-care system and scientific innovations present new challenges to the specialty. This leads to questions about priority, problem areas and weaknesses as well as to new opportunities for the field and the overall question if it will be possible to meet the paradigm shifts and problems by the creation of new structures. In the light of the need for and the potential of design measures, this article presents a SWOT analysis of the specialty's situation as a whole and in particular for gynaecology in German universities. One sees additional demands that add up to an expansion of the tasks. At the same time the shortage of new recruits becomes apparent. A broadening of the perspectives on women's health and individualised medicine come into focus. Partial solutions include new supporting structures, capacity measurements as well as even structural options. In particular, the department structure, that is common abroad, opens an opportunity for specialisation while maintaining unity for a broader further training and strengthened research. Chances and strengths of the specialty are especially effective in coordinated and concerted activities.

\section{Zusammenfassung \\ $\nabla$}

In einem großen und sehr vernetzten Fach wie der Frauenheilkunde ist es im Hinblick auf die $\mathrm{Zu}$ kunftsfähigkeit eine besondere Herausforderung, exzellente Krankenversorgung, Forschung und Lehre zu gewährleisten. Gleichzeitig stehen sowohl Kliniken als auch Forschungseinrichtungen unter einem zunehmenden Leistungs- und Wettbewerbsdruck, um klinisch, wissenschaftlich und wirtschaftlich bestehen und sich weiterentwickeln zu können. Die zahlreichen Veränderungen, auch Paradigmenwechsel, in Medizin, Gesellschaft, Gesundheitssystem und wissenschaftliche Innovationen stellen das Fachgebiet zudem vor neue Herausforderungen. Daraus entstehen Fragen nach Prioritäten, Problemfeldern und Schwächen, aber auch den Chancen des Faches und münden in die übergreifende Frage, ob es der Schaffung neuer Strukturen bedarf, um den Paradigmenwechseln und Problemen begegnen $\mathrm{zu}$ können. Mit Blick auf die Gestaltungsnotwendigkeiten und -potenziale widmet sich diese Arbeit einer SWOT-Analyse zur Situation des Fachgebiets insgesamt und speziell für die universitäre Frauenheilkunde in Deutschland. Es zeigen sich zusätzliche Anforderungen, die sich zu einer Ausweitung der Aufgaben summieren. Gleichzeitig zeichnet sich Nachwuchsmangel ab. In den Fokus rücken die Erweiterung des Blickwinkels auf die Frauengesundheit und die individualisierte Medizin. Die Lösungsansätze schließen neue Supportstrukturen, Kapazitätsbemessungen, aber auch strukturelle Ansätze ein. Insbesondere die im Ausland bereits übliche Departmentstruktur eröffnet Möglichkeiten zur Spezialisierung unter Erhaltung der Einheit, für eine breite Weiterbildung und gestärkte Forschung. Chancen und Stärken des Faches werden insbesondere im abgestimmten, gemeinsamen Handeln wirksam.

\footnotetext{
* The first two named authors contributed equally to this work.
} 


\section{Introduction}

$\nabla$

\section{Approach to the topic}

The numerous changes in society, the health-care system and scientific innovations provide new challenges for the specialty. For gynaecology as a large and heavily networked medical discipline, a particular challenge is to provide excellence in hospital care, research and training. At the same time this is especially important with regard to sustainability since not only hospitals but also research facilities are facing increasing performance and competitive pressure in their clinical, scientific and economic attempts to survive and to develop further.

\section{Description of the problem}

The spectrum of the specialty is huge and ranges from prevention and early detection through to conservative and surgical therapy and aftercare. Psychological and social-medical aspects are also present [1]. Women and their health, encompassing all phases of their lives, are at the centre point. The complexity of the field becomes even more obvious on looking at the many special working and interdisciplinary fields that are gaining in significance with the breakdown of the interfield boundaries. Looking to the future, the specialty will be faced with numerous problems. This will lead to a search for new processes and structures to help overcome the problems and to create space for a new orientation.

A paradigm shift to a focus on health is steadily underway in society and in the health-care system. A paradigm shift in research results from the advances in (biomarker-based) individualised medicine. In addition, there are changes in society that are reflected in changing conditions for medical health-care supply. The complexity of the field increases the risk of losing its unity. Beside the maintenance and further development of competence in the core areas and special segments of the field as well as their uniformity, for the future of the specialty, the next generation of clinicians and researchers is of fundamental significance. In view of the number of open positions and unoccupied chairs (e.g., more than one hundred vacant head physician positions in German gynaecological clinics in 2013) [2] and the economic pressures in the health-care related field of tension [3-5], an increasingly existential problem is approaching. The specialty is experi- encing ever increasing competition from other medical specialties, e.g., concerning competence, financial support for research, national and international visibility and, last but not least, the next generation of physicians.

All of the mentioned developments are causes of concern for the entire specialty gynaecology.

For facilities of different care levels within the graded German health-care system, beginning with district and general hospitals through to maximum and university care, many of the problems overlap. Others are specific for the facility or apply to particular segments such as, for example, facilities of a certain level in the framework of the graded health-care supply for complex obstetric-perinatal care.

For the university facilities, there is the additional special challenge of academic teaching and research. This includes the integration of research and its visibility in international comparison as well as the obligation to represent the specialty internationally in the best possible manner. In the following paragraphs the special problem fields of university facilities are presented separately from the specialty-related perspectives.

\section{Specific issues}

The open questions for the future of the specialty can be collected together in topic complexes that each contain a multitude of aspects. Some of the most important are mentioned as examples in - Table 1 and reflect the selection with which this article is concerned.

Taking an overall view, requirements for future design options can be deduced - for the specialty as a whole and especially for university clinics.

\section{Methods \\ $\nabla$}

Discussed in the present article are the above-mentioned specific issues from the viewpoint of the specialty gynaecology in general, supplemented with special aspects of university gynaecology. After an initial situation and problem analysis, suggestions for possible solutions are listed. Reference is made to the structural possibilities presented in the 2012 structure paper of the German Society for Gynaecology and Obstetrics (Deutsche Gesellschaft

Table 1 Specific issues.

\begin{tabular}{|c|c|c|}
\hline & Specific issues & Partial and supplementary aspects \\
\hline 1 & What are the current challenges? & $\begin{array}{l}\text { Are there paradigm shifts in medicine and society that have to be considered for the challenge? } \\
\text { Does the focus on women's health have priority? } \\
\text { How can the realisation that modern gynaecology and obstetrics have to be integral } \\
\text { be implemented? }\end{array}$ \\
\hline 2 & \multicolumn{2}{|c|}{ What are not only the problems and weaknesses but also the strengths and chances of the specialty? } \\
\hline 3 & $\begin{array}{l}\text { Do new structures need to be created in order } \\
\text { to address these challenges? }\end{array}$ & $\begin{array}{l}\text { What structure should the modern specialty have? } \\
\text { Is it necessary to restructure university women's hospitals? } \\
\text { - How can the focus on women's health and the demand for integration be implemented? }\end{array}$ \\
\hline 4 & $\begin{array}{l}\text { How can the unity of the specialty be achieved? } \\
\text { Note: Even if this question applies to all fields, } \\
\text { some aspects are specially directed at university } \\
\text { women's hospitals. }\end{array}$ & $\begin{array}{l}\text { How can all important subject facets be included? } \\
\text { or creation of the subdisciplines? } \\
\text { - How can research be integrated? } \\
\text { - How can the necessary balance between clinical work and research be achieved? }\end{array}$ \\
\hline 5 & Are new leadership structures needed? & - How can the international excellence of the specialty be maintained and expanded in Germany? \\
\hline 6 & \multicolumn{2}{|c|}{ Which strategies can counteract the recruitment problem? } \\
\hline 7 & \multirow{2}{*}{\multicolumn{2}{|c|}{ What are the perspectives against the backdrop of the generation change? }} \\
\hline 8 & & \\
\hline
\end{tabular}


für Gynäkologie und Geburtshilfe [DGGG]) [6]. This then leads to a discussion of the question if and to what extent a restructuring of the specialty is needed and meaningful. First of all a SWOT analysis (SWOT: strengths, weaknesses, opportunities, threats) on the situation of the specialty and in particular for university gynaecology is undertaken, based on quality data from the German health-care system (on processes, structures and results) of gynaecological clinics and, in particular university departments of gynaecology, in addition, reference is made to bench-marking results presented in the literature, the national quality reports and the requirements of the legal framework. Furthermore, a problem-centred literature search was undertaken for analyses, conceptions and strategy papers on the status and further development of the specialty and another international search for best practice models on the structure of departments of or, respectively, centres for women's health.

The searches covered the period 2010-2013 in the Medline databank of NIH (PubMed), in DIMDI, in the databanks of the International Network of Agencies for Health Technology Assessment (DARE, the database of abstracts of reviews of effectiveness/abstracts of quality assessed systematic reviews, NHSEED, NHS economic evaluation database/economic evaluations of health-care interventions, and HTA, health technology assessment database/ publications and projects by INAHTA and other HTA organisations). Sources freely available in the internet were included in the searches, as were journals not covered by medical databanks on the topics women's health, gynaecology, and health-care quality. Also included were the pages of the national health monitoring system and national quality reporting system (e.g., AQUA, National Association of Statutory Health Insurance Physicians, Federal Joint Commission) and quality-related internet pages of individual medical institutions. As explicitly stated in the literature [7], especially for the topic quality manual searches have a major importance alongside electronic databank searches. Thus, a manual search was undertaken on the basis of already identified publications and web sites. The following terms, singular and plural (individually as well as in combination and also in english translation) were employed: women's health, gynaecology, department, teaching, standard, (health-care) quality, structure, university medicine, further training, centres.

\section{Results}

$\nabla$

Challenges for the specialty gynaecology and obstetrics Overview of the specialty as a whole

As already mentioned, challenges to the specialty arise from different sides, to name just a few: increasing specialisation [8], the further development of procedures, methods, practices and the ever changing conditions (also from the side of the legislature) [9-11]. The demographic changes impact equally on clinical pictures, tasks and the employment situation. In addition there have been various paradigm shifts.

Are there paradigm shifts in medicine and society that need to be taken into account? A significant paradigm shift in research has initiated advances in the (biomarker-based) individualised medicine: away from treatment concepts that are useful for as many patients as possible towards therapies that bring the best possible health-care benefits for the individual patient. The self-determination in health-care issues (e.g., the cancer plan implementation law) as wanted by the legislature, communication and nocebo research, all give rise to extended requirements in patient orientation and communication. The nocebo effect - also known as the negative placebo effect - is based, among others, on specific expectations about a therapeutic intervention, e.g., drugs or clarification. If the negative effect predominates, we speak of a nocebo [12]. At the same time, new research results suggest that patients want to find their own way to a decision and to self-determination especially during the patient-doctor contacts.

The paradigm shift in society and in the health-care system towards the focus health and health promotion, which has been continuously ongoing for several years, has not bypassed the field of gynaecology. Should the specialty follow this focus, it would mean that women's health will be the main topic for the future. Women's health extends beyond the medical field of gynaecology, is interdisciplinary and encompasses social-cultural environments and societal aspects in its field of view. This requires extended competences in the context of the specialty. As is reflected in the new competence-based learning target catalogue, a process is underway in medicine that places the boundaries of the specialties in the background and emphasises general competence and specialised skills and knowledge. Competence-oriented learning targets are, in contrast to many other countries, not yet available for medical students in Germany at a national level. The target is a catalogue oriented to the professional image of physicians. The standing conference of education ministers is aiming at an educational reform that will place competences for physician's actions in the spotlight. The licensure laws for physicians and the EU directive 2005/36/EC define the framework. The catalogue is currently being prepared in cooperation with a committee of experts [13]. Thus, the way is being paved for a new fragmentation of medicine, including the specialty gynaecology, or the way to the discovery of a new interdisciplinarity. At the same time a continuous transition of the individual specialties and their multi-facetted, similarly competence-oriented training curricula is being prepared which will then be collected together in the new exemplary further training plans of the federal chamber of physicians (see below). Already today, however, the further education plans for gynaecology are mapped out in their entirety in only a few institutions. Thus, a temporally as well as didactically structured basic training is becoming more and more important as is reflected, for example, in the structure and content of the training programmes of the German Academy for Gynaecology and Obstetrics (Deutsche Akademie für Gynäkologie und Geburtshilfe [DAGG]) [14], the German Academy for Senology (Deutsche Akademie für Senologie) [15] or at the European level in the proposals of the European Board and College of Obstetrics \& Gynaecology (EBCOG) [16]. The international perspectives will gain increasing significance in future training programmes.

Is the focus women's health a priority? Health is becoming a central aspect in all branches of society. The Tallinn Charta (2008) of the WHO with its motto "Health in all Policies" [17], which places responsibility for health and prosperity on the health-care system, is just one example. Those who already place health/ women's health in the spotlight are also willing to include other factors impacting on health into research and medical activities. This is the chance for medicine as a whole and for the specialty: the point of view expands beyond illness/being ill and treating illnesses. Since gynaecology, as has been documented in numerous successfully applied prevention programmes over the years, has encompassed the expanding field of action for a long time, the formal prioritisation of women's health represents an obvious and forward-looking step for the specialty. 
The claim to a pronounced competence of the specialty for the issue women's health is based on its knowledge, as well as its clinical and scientific experience in the health of women.

Gynaecology should open up to this extended understanding of its tasks, if it does want not to lose important parts of its own sphere of influence such as prevention and health promotion for women [18]. Since outstanding commitments in prevention, especially in gynaecology and obstetrics, were excellent examples for the many developments in this field, it must be in the interest of the specialty to demonstrate its medical competence and leadership. Developments in training programmes that concern health in the absence of medical expertise cannot be in the best interests of gynaecologists who have always been involved in the health of mother and child, as for example in obstetrics, and of girls and women of all ages. The history of perinatal examinations alone reveals that the specialty has never only been concerned with fighting disease. The care of pregnant women is an excellent example for the beneficial meshing of health promotion, prevention and the transition to therapy when required [19]. This comprehensive approach thus characterises the self-perception of gynaecologists and allows the refocusing on women's health within the specialty to rather be understood as a change in terms than a paradigm shift.

Health in the focus means, with a glance at research, the demand for increased research into prevention and supply, which additionally addresses health-related factors from the specific world of women. At the same time there is an increased need for educational programmes for the development of health competence and evidence-based prevention - supplementary to the curative tasks in gynaecology - with the objective to prospectively minimise the burden of disease by preventative measures.

How can knowledge be applied so that modern gynaecology will become holistic? Widely differing factors impact on the health of women: these include, for example, environmental conditions as well as social burdens, particular lifestyles or genetically caused health risks [20]. The specialty meets the demands for a holistic approach with trends and offers which can no longer all be integrated in the field but rather which gain, in a vast variety, a place alongside the offers of the specialty. At the same time there is growing recognition that the exclusion of context and personal needs in a DRG-oriented hospital landscape ultimately leads to an impairment of the clinical outcome as well as to problems in adherence and communication. Adjustments to differences in value are challenges that have to be met, not only with regard to the demands of an increasing self-determination in questions of health. If the specialty does not respond to demands from the side of the patients and health politics, namely to offer the competences of the specialty from a holistic point of view, this will lead to the patients turning to other fields (naturopathy, psychology, nutritional and sport science, etc.) in order to present their problems there. This involves disadvantages, e.g., the overview is lacking, medical requirements are not sufficiently considered, and adherence suffers.

\section{Special situation of university gynaecology}

Because of their particular tasks in research and teaching, university facilities face additional challenges. In teaching new routes are being sought, characterised, for example, by the emphasis of the NKLM on competences instead of specialties or due to a general didactic rethinking. This is continued with the target of developing a competence-based model education regulatory of the specialties, and thus also for gynaecology. The further training plans should preferentially be defined in further training blocks (originally competence blocks) and further training modes (formerly competence levels) rather than in time periods. Also the required volumes should be adapted to the actual medical care situation. The further training should be based on the question "which competences does a physician need in order to function independently as a specialist?" [21]. However, an increase of the financial sources does not seem to be possible so that, possibly, cross-subsidisations will have to be used further. A focus on health and personalised medicine, including consideration of gender aspects, demands further additional interdisciplinary research efforts with an institutionally strengthened research structure in order to support highly specialised research segments. This naturally leads to questions about the (internal) structure of the modern specialty and about suitable structures for a university gynaecology department. For this, first of all not only the weaknesses and deficits of the current situation but also the existing strengths and opportunities that may be trail-breaking for future structures must be assessed.

\section{SWOT analysis ( $\odot$ Fig. 1 ) Strengths}

The specialty gynaecology has a high relevance. It continues to guarantee in Germany a qualitatively high-value patient care over the entire width of the field and for girls and women of all age groups.

Both inpatient and outpatient sectors make their contributions to this.

This quality as illustrated by the obligatory quality assurance in hospitals as well as the quality assurance schemes in the scope of the German Physician's Association. The base is the graded health-care system in the inpatient sector, supplemented by an outpatient care system networking also with the inpatient structures. Regionalisation in obstetrics, for example, has a long tradition and is now successfully supplemented by a graded neonatal care system according to the guidelines of the Joint Federal Committee (Gemeinsamer Bundesausschuss [G-BA]) (quality assurance guidelines for preterm and term babies/QFR-RL) [22].

Numerous voluntary benchmarking and quality assurance initiatives, national and to an increasing extent also international certification of facilities and organ centres (DKG, DGS, EUSOMA, KTQ DIN ISO, EBCOG, AGO) additionally reflect the scope of work and are, last but not least, an expression of high personal engagement. The legislature for its part is more concerned with obligatory quality initiatives [23]. The law for the further development of finance structures and quality in statutory health insurances will come into force on January 1, 2015 and includes the creation of an institute for quality assurance and transparency in the health-care system. This should, as an advisory capacity for the $\mathrm{G}-\mathrm{BA}$, recognise the existing deficits in the health-care system, work towards specific improvements in treatment and strengthen transparency. Also the institute should contribute to more transparency regarding the quality of health-care, for example, by comparisons of the quality of hospital services [24].

The diversity of content and complexity of the specialty help to make it attractive. 


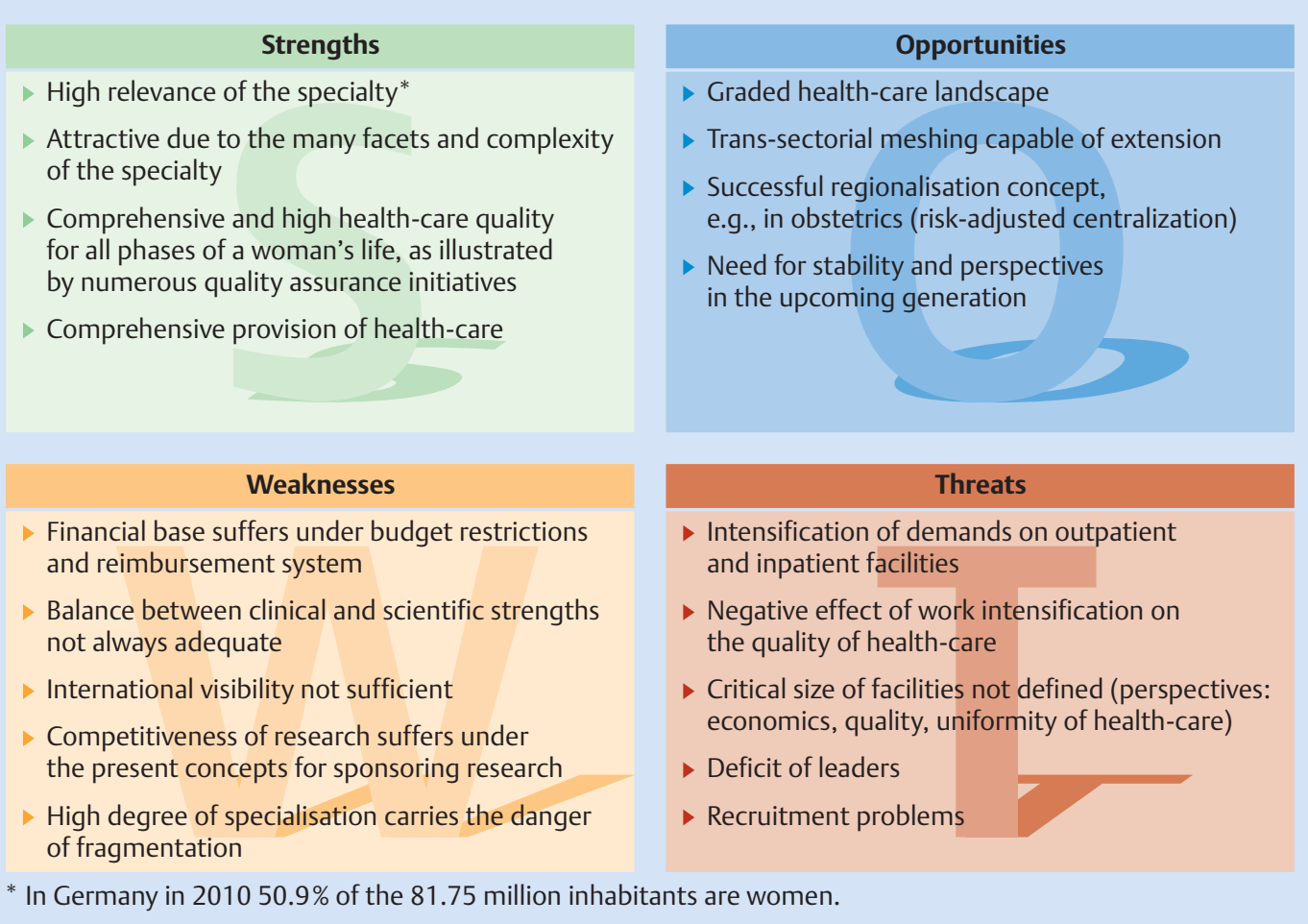

\section{Strengths}

High relevance of the specialty

Attractive due to the many facets and complexity

Comprehensive and high health-care quality for all phases of a woman's life, as illustrated by numerous quality assurance initiatives provision of health-care

Fig. 1 SWOT Analysis on the Situation of the Specialty.
Contributing to its image among the next generation of physicians are high-value qualification measures supported by the professional societies as well as the perception of medical care in the facilities participating in basic and advanced education in all fields of medicine. The complexity, however, also brings the danger of fragmentation and calls for a more conscious and responsible bundling of competences.

\section{Weaknesses}

The financial foundations of the specialty suffer from the budget restrictions and the reimbursement system.

This holds not only for the outpatient but also equally for the inpatient sectors and precludes a sustainable security in planning for hospitals and practices [25]. The field of prevention in particular has no independent financial footing. Finance concepts that support intersectorial cooperation are hardly available at present. The special mandate to provide care of facilities such as, e.g. university medicine, also requires, just like, for example, case severity and complexity or holiday surcharges that each require a separate appraisal in reimbursement systems (e.g., DRGs, EBM) in order to guarantee an appropriate financial basis for hospitals and practices [26]. Holistic medicine and especially medical communication performance, the importance of which is explicitly emphasised in the law on patient rights and the national cancer plan, are not recognised [27]. In perspective, the quality of health-care cannot remain unaffected by this.
The necessary balance between clinical strengths of a facility and science has often not been reached in all fields.

An in-depth knowledge of clinical science with corresponding top reputation is, in many places, not completely represented, especially from basic research and translational considerations. There is a need for improvement here in both structures and personnel. This is of special interest from the viewpoint of university hospitals.

The international visibility and significance of German gynaecology is upgradeable especially in the research sector.

With regard to participation in high-volume, complex international research projects, at present only limited competitiveness exists. This could be disadvantageous for the acquisition of topclass scientists and for the attractiveness of gynaecology in Germany.

\section{Opportunities}

The high-value, graded health-care network can offer opportunities for complementary further development and synergy.

Thus, for medical problems of differing urgency and severity, diagnostic and therapeutic means are available at different healthcare levels oriented to the individual needs of the patient. Further expansion of the, in many cases exemplary and far reaching, regionalisation concepts in gynaecology, together with tran- 
sectorial networking supported by suitable financing structures offer possibilities for bundling. Synergies from networks such as, e.g., those realised in oncological centres exist. University facilities can - in accord with their unique and exclusive features - offer high-end medicine complementary to the corresponding research, and at the same time open up potential for optimisation.

\section{Problem areas}

A densification of requirements can be observed.

The reasons for this are not only social expectations and developments, but also consequences from the current reimbursement structures. This holds for both hospitals and practices. Work intensification is followed by increasing pressure on performance and competitiveness in order to survive clinically, economically and scientifically $[28,29]$. The consequences of this work intensification and its effects on health-care quality are only now becoming the subject of scientific investigations which, however, are clearly revealing the dangerous potential [30].

Critical size of facilities - from economic and/or qualitative points of view?

If all facilities offered all services, this would carry the danger of a fragmentation of the health-care landscape as well as of an oversupply and an unfinanceable situation. At the same time SGB V § 70 demands a uniform health-care supply. Especially in rural districts a thinning out of the health-care landscape is to be feared. There are increasing indications of this especially regarding gynecologic and obstetrical care [31].

There is an urgent need for research, discussion and organisation among the ranks of the specialty on this entire problem area. Technically well-founded findings should be included in appropriate regulations by the decision making bodies of the healthcare services. The critical size is gaining importance in connection with the qualification of young professionals.

A nationwide deficit of qualified leaders with clinical and scientific expertise is becoming apparent. There is a lack of young talented personnel qualified in the entire width of the specialty.

In the specialty gynaecology and obstetrics, there is at present an enormous problem in finding young talent to fill executive positions. Many head physician positions and even chairs cannot be occupied adequately. At present there are about 30\% part-time positions. A discontinuity in expertise or even a decrease in the number of motivated, high performing young talents is to be feared [1]. The problem area can in the mid-term take on the character of a threat to continuity in gynaecological and obstetrical services, and in university hospitals also to further advances in research. In the meantime gynaecology and obstetrics, like general medicine, belong to the patient-centred fields for which further training is sponsored by the association of statutory health insurance physicians (Kassenärztliche Vereinigungen) [32]. These problems are fuelled by various fields which when taken alone each number among the problem areas: for example, the increasing subspecialisation, also in the profile of individual facilities, or a generation change in the medical profession. In parallel there is an increasing need for stability and perspectives for the upcoming generation of medical students [33] as well as for physicians in the process of obtaining their qualifications [34]. The brain drain to other countries and professions other than those in clinics or practice sends a clear message.

\section{Creation of new structures}

The confrontation with the paradigm shift and a glance at the strengths and weaknesses allows for considerations about where and what starting points exist which will support the sustainability of the specialty.

What must be mentioned - already at this point: new ways and structures within the specialty also require a rethinking in neighbouring fields such as, for example, research funding, science policies, university personnel structures or the financial basis of medical care. This remains to be taken into account in the following paragraphs since efforts to overcome the actual problems within the specialty itself frequently reach limits.

To broaden these limits caused by external influences is, in parallel to internal optimisation, one of the specialty's most important tasks, in the decision-making bodies, e.g., self-government or research. A continuous coordination within the specialty enables for similar activities of many participants. This will be discussed in more detail below.

\section{What structures does the modern specialty need} and what (re)structuring of a university hospital does this need?

All the previously mentioned problems aim at a reorganisation to give the specialty breadth and flexibility. The concrete question concerns the choice and the necessary steps needed for its realisation which include, beside the new substantive definitions and the setting of priorities, also a reorganisation of structure(s). A structuring model, derived from the previous analyses for university facilities, is the establishment of a department. The realisation of this option is described elsewhere. A part of the undertaken structural changes will probably prove to be transferable to other institutions with different service mandates.

\section{How can the focus women's health and the claim for holistic medicine be realised?}

With the orientation towards health and through the incorporation of influencing factors outside of medical care, the specialty considers the woman as a whole in her social and psycho-sociocultural activates and grasps the opportunity to build up a personal relationship with the girl or women through the various phases of life, first as an interested person, then as someone to be advised and finally if necessary as a patient. In a holistically oriented gynaecological institution the girls and women can find a refuge and competent contact persons for the widely differing situations during the course of their lives. A department or centre for women's health committed to this prioritisation includes additional elements and task areas into its structures and portfolio.

\section{Uniformity of the specialty}

To maintain the unity of the specialty is a primary goal. The following questions back this up:

How can all important facets of the specialty be retained? Which strategies are available for the preservation or respectively, creation and extension of subdisciplines? Attention needs to be paid to various flows that work against cohesion: 
i. If in future an increasing number of subdisciplines can either not be adequately involved and/or find from their own point of view no room for further development, this will endanger the cohesion. Fragmentation will occur. At the same time the further training in the subspecialties will be endangered since the group competence is lacking.

ii. In parallel, effective but almost unnoticed, processes are ongoing in various levels of medicine that will further blur the borders of the specialty. What on the one hand may be useful for an increase in inter- and transdisciplinarity, on the other hand can also carry the danger that the overview and the clinical experience for integration may be lost - at the expense of expertise referred to clinical entities, but also possibly at the cost of the patients.

iii. In addition to tendencies suggesting that the subdisciplines are striving for autonomy, some parallel developments and/ or uncoordinated activities in various topics are harmful to the unified voice of the specialty and could lead to mutual alienation and unproductive competitive situations. Coordination and understanding deficits can be observed not only between the subfields but also between the sectors. These developments weaken not only the specialty in achieving common targets, for example, with respect to health policies but also the unity in medical affairs.

The first two mentioned developments (i, ii) concern above all university gynaecology and obstetrics which has to combine all facets of the specialty in one facility together with the corresponding teaching and research tasks. Accordingly university gynaecology and obstetrics gains a sort of pace making function for answering the issues. The department structure offers itself as a pioneering option. For the last mentioned item (iii), possible solutions are already sketched out in the search for common objectives and in improved coordination, for example, on the platform of the professional societies (e.g., a senate of the specialty). In addition discussions must be initiated within the specialty as to how in future all facets should be represented in the breadth of the health-care landscape.

\section{How can research be integrated?}

Advances in medical research are in the meantime occurring more and more with breath-taking speed but also isolated from clinical practice. With almost the same speed, knowledge is decreasing about what is really entering into health-care and care of the individual patient. Suitable (health-care) structures must be sought so that all patients who are in need of it can profit from the advances - this problem field will be potentiated in the areas of genome- and biomarker-based, individualised medicine [35]. Still equally important is that issues from routine practice also find a way into research questions. Due to the high demands of hospitals with their considerable intensification of work in the past few years, the free space for associated research has become smaller, although the willingness and interest of clinically active personnel are still unabated.

The suggestion has been made to deconcentrate the fields of research, teaching and clinic without their losing contact with one another. Physicians employed in science, also known as physician scientists, can be considered as a solution to increase research [36]. Such medical doctors possess the special and ultimately characterising perspective of direct patient contact that is so important for research in the field of gynaecology and obstetrics. A personal willingness or, respectively, interest in research, however, needs to be embedded in appropriate structures that make research possible as a "collective enterprise" [37]. Research and researchers should be able to count on stable support from the side of the facility. Research and its results are not consistently predictable - also not at the level of soliciting external funds as a basis. The department structure as an organisation model that creates common space for all functions of the specialty - as can be seen by a glance across national borders - concomitantly opens free space for various special activities both in clinical and research areas. The practical possibilities for realisation are provided by the intermeshing structures under the umbrella of the department [9]. The two organisational units combined in a department also contribute to academic teaching in specific, predetermined proportions deriving from their assignments within the department. This is achieved on the one hand by supplementary aspects that arise from the expansion of topics within the department and, on the other hand, by the integration of leading scientists with an exemplary function for young researchers. Both aspects are in accord with the aims of the NKLM, namely to focus more strongly on research in further training.

\section{New leadership structures}

The self-perception of all disciplines and subdisciplines to be an integral part of the specialty is based finally on the self-image of the respective areas, assignments of specific responsibilities in the framework of a facility and, in the university context, on the presence of professorships.

Again principally for university facilities and their special tasks is the search for leadership structures that simultaneously support the integration of all subdisciplines, research and teaching as well as their visibility and individual characteristics. A department structure makes such autonomy and task assignments possible in modules, with an executive board to simultaneously ensure the unity of the institution. The definitions of health-care organisation and quality by the department's executive board encompass equally all facets of the specialty. This requires as a matter of priority the strengthening of existing and the consolidation of still unfilled scientific fields to become the pillars of a modular network. This modular structure provides the department with room for innovative processes and for new ways in the deployment of personnel resources [9].

\section{Recruitment problems}

It is becoming increasingly difficult to recruit new personnel in the breadth of the specialty and for all specialisations and to support a continuous development of competences. In the context of university gynaecology and obstetrics this furthermore holds for the qualification of academic leaders and creation of the prerequisites for excellence in research and teaching. Structured further training is being increasingly hindered by organisational and personnel bottlenecks [1]. Despite their high specialisation, many hospitals can only offer fragments of further training [38]. At the same time there is a desire for broad and practice-oriented further training and, last but not least, this should include research and research competence. To make possible a structured clinical further training in combination with a scientific career pathway represents a particular challenge, although the greatest sustainability is to be expected from training in an integrated science. For further training at universities the department structure also offers suitable opportunities for this. The department can thereby represent a crystallisation centre from which further training concepts can be anticipated, tested and coupled to the health-care landscape. For the last step in particular the professional societies 
can play a significant role as has been demonstrated by the numerous activities of the DGGG and its academies.

\section{Implications of the generation change}

The danger that a (university) women's hospital will lose highly qualified and clinical scientific-oriented leaders must be effectively thwarted in that structural changes be made to increase the attractiveness of a location to ensure long-term employment of personnel or, respectively, to aid recruitment of new personnel. This requires suitable perspectives not only from the viewpoints of subject matter but also of organisation (see below). Such broadened options offer the composite of a department a unified leadership structure even in the light of increasing subspecialisation and changing profiles of leaders.

\section{Consequences of the demographic changes}

Completely new demands - in all respects - have in the meantime arisen from our dealings with the societal process of the demographic changes. This concerns on the one hand questions arising from an increase of gynaecology for the elderly and on the other hand questions arising from the future human resources, all gynaecological clinics and outpatient facilities are equally affected by this.

Gerontogynaecology will gain more and more prominence with the increase in chronic and oncological diseases, not only in clinical routine but also in outpatient practices. The need for supporting structures and interdisciplinary competence will increase [39] together with the need for new capacity determinations for hospitals of different care levels and for the doctor's practices. The graded health-care system with the guideline "outpatient before inpatient" needs supplementary definitions, also in the reimbursement system that takes the additional requirements into consideration. The problem of reimbursement for extraordinary services and for taking on responsibility also needs to be discussed in this context. People who work in health-care and those in need of nursing care, the numbers of whom are increasing due to the demographic changes (in 20303.4 million [status quo scenario] people in need of nursing care are expected [40]), present to the specialty with new disease constellations. Research on and appraisals of the problems, although urgently needed, are mostly lacking $[41,42]$. They are, however, a necessity for considerations as to what steps are to be taken in order to be prepared for these challenges in the entire breadth of health-care.

Changes in population and age structure (e.g., increasing mobility, single person households, demographic changes with an increase in domestic care engagements) also bring about a need for matching working places and further training chances, especially since the mentioned recruitment problems forbid a renunciation of resources [43]. It is still the female physicians and researchers who have high engagements in family care obligations of varying types [44]. A change is already becoming apparent due to social developments (gender mainstreaming, value shifts, among others). Opinions vary as to whether the "value shifts" are in the centre of attention for the younger generation or whether it is adjustment strategies to professional, social and structural changes (e.g., short fixed-term employment contracts in research).

\section{Recapitulative Assessment and Conclusions $\nabla$}

The specialty is faced with various medical and societal currents and the task to appropriately adjust to the new situations. The complexity demands first of all an analytical synopsis of the present situation. All the presented challenges contribute to additional demands for the specialty. They add up to an expansion of the tasks. Prerequisites for solutions to the upcoming challenges were sketched out along with the questions mentioned above (see the Introduction). The presented starting points to overcome the problems require a stepwise approach. First to come into question are models (and their evaluation) in the context of the German provisional system.

Proposals by the DGGG for the scientific further development and structure of the specialty gynaecology and obstetrics with a view to the German universities were recently published. There it is stated that a university hospital in the Anglo-American countries as well as in many European countries without specialised divisions in a department structure is not conceivable. Thus also the larger clinical and scientific facilities for gynaecology and obstetrics in the other German-speaking countries are organised accordingly. This structure supports, so the expectation of the structure recommendations, the comprehensive education of students and further training in the specialty or, respectively, its focal topics (gynaecological oncology, special obstetric and prenatal medicine, gynaecological endocrinology and reproduction medicine). When establishing a department, the tasks of the divisions in patient care and teaching according to the respective topics should be precisely defined, overlapping avoided, and an intensive cooperation not only between the divisions but also between centres should be sought in the interests of comprehensive and qualified patient care [45]. The exemplary implementation of these DGGG proposals in Germany has to start. This is currently being realised in the Department of Women's Health in the hospital of the University of Tübingen $[8,9]$.

The structuring of the speciality beyond the university context remains as a separate focus, in orientation on the presented key objectives and starting points as well as updated recommendations. Many problems can only be addressed in cooperation with all fields of health-care. The chances and strengths will be especially effective through collective action.

\section{Conflict of Interest}

$\nabla$

None.

\section{References}

1 Kreienberg $R$. Wir müssen uns den Herausforderungen stellen. Gynäkologe 2010; 43: 723-724

2 Department für Frauengesundheit. Universitätsklinikum Tübingen. Strategiekonzept 2013 (unveröffentlicht)

3 Beckmann MW. Frauenarzt/-ärztin der Zukunft. Müssen die Kliniken neu strukturiert werden? Gynäkologe 2010; 43: 748-756

4 Beckmann MW, Bader W, Bechtold I et al. Financing and financial problems of care and structures in the field of gynaecology and obstetrics in the year 2011 - general aspects and obstetric care. Geburtsh Frauenheilk 2011; 71: 367-380

5 Beckmann MW, Bader W, Bechtold I et al. Financing and financial problems of care and structures in the field of gynaecology and obstetrics in the year 2011 - DRG system and inpatient care with urogynaecology and benign and malign gynaecological surgery. Geburtsh Frauenheilk 2011; 71: 497-510 
6 Louwen F, Ortmann O, Strowitzki T et al.; Deutsche Gesellschaft für Gynäkologie und Geburtshilfe. Vorstellungen der DGGG zur wissenschaftlichen Weiterentwicklung und Struktur des Faches Gynäkologie und Geburtshilfe an den deutschen Universitäten. Geburtsh Frauenheilk 2012; 72: 777-779

7 Mogyorosy Z, Mogyorosy G. Critical appraisal of articles about clinical audit. Orv Hetil 2007; 148: 985-991

8 Brucker SY, Simoes E, Wallwiener D. Zukunft der universitären Frauenheilkunde: ein Department für Frauengesundheit? Geburtsh Frauenheilk 2014; 74: 801-809

9 Simoes E, Brucker SY, Krämer B et al. University gynaecology and obstetrics, quo vadis? A department of women's health - university women's hospital of the future? Arch Gyn Obst 2014; DOI: 10.1007| s00404-014-3401-7

10 Hoopmann $M$, Abele $H$, Wagner $N$ et al. Sonografische Bestimmung des Höhenstandes des fetalen Conus medullaris im Laufe der Schwangerschaft. Ultraschall in Med 2010; 31 - V1_02

11 Wöckel A, Kreienberg $R$. Weiterbildung gestern, heute und morgen. Konzept der Deutschen Gesellschaft für Gynäkologie und Geburtshilfe. Der Gynäkologe 2010; 43: 725-730

12 Flaten MA, Simonsen T, Olsen $H$. Drug-related information generates placebo and nocebo responses that modify the drug response. Psychosom Med 1999; 61: 250-255

13 Medizinischer Fakultätentag. Arbeiten am Nationalen Kompetenzbasierten Lernzielkatalog (NKLM). Online: http://www.mft-online.de/ presse-standpunkte/telegramm/arbeiten-am-nationalenkompetenzbasierten-lernzielkatalog-nklm; last access: 03.07.2014

14 Deutsche Akademie für Gynäkologie und Geburtshilfe. Online: http:// www.dggg.de/akademie-dagg/; last access: 03.07.2014

15 Dgs Deutsche Akademie für Senologie GmbH, Berlin. Online: http:// web2.cylex.de/firma-home/dgs-deutsche-akademie-fuer-senologiegmbh-10700245.html; last access: 03.07.2014

16 EBCOG - European Board and College of Obstetrics and Gynaecology. Online: http://www.ebcog.org/; last access: 14.08.2014

17 WHO (Europa). Die Charta von Tallinn: Gesundheitssysteme für Gesundheit und Wohlstand. 2008. Online: http://www.euro.who.int/ __data/assets/pdf_file/0004/88609/E91438G.pdf; last access: 25.04.2014

18 Simoes E, Wallwiener D, Kusicka $H$ et al. Health literacy requires empowerment - results of an analysis of patient needs and the demand for qualification over a 10-year period. Geburtsh Frauenheilk 2013; 73: $1023-1027$

19 Simoes E, Kunz SK, Münnich R et al. Informed Consent bei der Entscheidung zum Kaiserschnitt - methodenbezogene Morbiditätsgradienten erfordern die Befähigung der Schwangeren. Geburtsh Frauenheilk 2010; 70: 732-738

20 Wilkinson R, Marmot M; WHO (Europa). Soziale Determinanten von Gesundheit: die Fakten. Online: http://www.euro.who.int/_data/ assets/pdf_file/0008/98441/e81384g.pdf; last access: 25.04.2014

21 Güntert A. Bundesärztekammer. Novellierung der (Muster-) Weiterbildungsordnung. Vortrag anlässlich der Delegiertenkonferenz der AWMF 10. Mai 2014, Frankfurt/Main-Flughafen. Online: http://www. awmf.org/fileadmin/user_upload/Die_AWMF/Delegiertenkonferenz/ DK-2014-05/TOP_13_Novelle-MWBO.pdf; last access: 03.07.2014

22 Gemeinsamer Bundesausschuss. Richtlinie des Gemeinsamen Bundesausschusses über Maßnahmen zur Qualitätssicherung der Versorgung von Früh- und Reifgeborenen gemäß § 137 Abs. 1 Nr. 2 SGB V in Verbindung mit $\S 92$ Abs. 1 Satz 2 Nr. 13 SGB V. Online: https://www.g-ba.de/ downloads/62-492-814/QFR-RL_2013-12-19.pdf; last access: 03.07.2014

23 Solomayer EF, Rody A, Wallwiener $D$ et al. Assessment of university gynaecology clinics based on quality reports. Geburtsh Frauenheilk 2013; 73: 705-712
24 Bundesministerium für Gesundheit. Gesetz zur Weiterentwicklung der Finanzstruktur und der Qualität in der gesetzlichen Krankenversicherung. Online: http://www.bmg.bund.de/fileadmin/dateien/ Downloads/Gesetze_und_Verordnungen/Bekanntmachungen/F/ FQWG/FQWG_Gesetzesentwurf.pdf; last access: 03.07.2014

25 Fiori W, Renner SP, Siam K et al. Shaping the system - the DRG evaluation project of the German society for gynaecology and obstetrics (Deutsche Gesellschaft für Gynäkologie und Geburtshilfe, DGGG). Geburtsh Frauenheilk 2013; 73: 776-782

26 Simon M. Das deutsche DRG-System: Grundsätzliche Konstruktionsfehler. DÄB 2013; 110: A-1782; B-1572; C-1548

27 Simoes E, Gostomzyk JG, Schmahl FW et al. Plädoyer für eine Stärkung der klinischen Sozialmedizin. Gesundheitswesen 2014; 76: 513-517

28 Stefl M. Common competencies for all healthcare managers: the healthcare leadership alliance model. J Healthc Manag 2008; 53: 360 374

29 Simoes E, Bauer S, Schwoerer P et al. Der strukturgebende Aspekt von Mindestmengenanforderungen im stationären Sektor. Das Gesundheitswesen 2005; 67: 96-100

30 Tucker J; UK Neonatal Staffing Study Group. Patient volume, staffing, and workload in relation to risk-adjusted outcomes in a random stratified sample of UK neonatal intensive care units: a prospective evaluation. Lancet 2002; 359: 99-107

31 Hibbeler B. Geburtshilfe in Gefahr. DÄB 2014; 111: B419

32 Deutsches Ärzteblatt aktuell. Hessen fördert angehende Fachärzte. DÄB 2014; 111: B414

33 Götz K, Miksch A. Die Sicherstellung medizinischer Versorgung und der Erhalt ärztlicher Arbeitskraft. Vortrag am 18.9.2013, Jahrestagung der Deutschen Gesellschaft für Sozialmedizin und Prävention „Gesundheit zwischen Wirtschaft und Demographie“, Marburg 2013

34 Ankowitsch E. Diskussion über den „Acht-Stunden-Arzt“. DÄB 2014; 111: B 417

35 Deutscher Ethikrat. Personalisierte Medizin - der Patient als Nutznießer oder Opfer? Tagungsdokumentation. Jahrestagung des Deutschen Ethikrats 2012. Online: http://www.ethikrat.org/dateien/pdf/ tagungsdokumentation-personalisierte-medizin.pdf; last access: 25.04 .2014

36 Scholz C, Friese K. Forschung im Fach. Wohin geht der Weg? Gynäkologe 2010; 43: 735-743

37 Fleck L. Entstehung und Entwicklung einer wissenschaftlichen Tatsache. Frankfurt am Main: Suhrkamp; 1980

38 Wöckel A, Kreienberg R. Weiterbildung gestern, heue und morgen. Gynäkologe 2010; 43: 725-729

39 Simoes E, Gostomzyk J, Schmahl FW et al. Klinische Sozialmedizin und Frauengesundheit. Geburtsh Frauenheilk 2014; 74: 626-630

40 Pfaff H; Destatis; Statistisches Bundesamt. Pflegebedürftige heute und in Zukunft. 2008. Online: https://www.destatis.de/DE/Publikationen/ STATmagazin/Soziales/2008_11/2008_11Pflegebeduerftige.html; last access: 25.04.2014

41 Simoes E, Wallwiener D, Ueding $E$ et al. Gesundheit von Frauen in Sorgeverpflichtung. Geburtsh Frauenheilk 2014; 74: 28-32

42 Hibbeler E. OP gelungen, Patient Pflegefall. Dtsch Arztebl 2014; 111: A-477; B-409; C-393

43 Simoes E. Frauen in informeller Pflegeverpflichtung. In: Gaertner T et al., Hrsg. Die Pflegeversicherung - Handbuch. 3. Aufl. Berlin: de Gruyter; 2013

44 Hancke K, Troth B, Kreienberg R. Familie und Karriere. Gynäkologe 2010; 43: 730-734

45 Louwen F, Ortmann O, Strowitzki T et al.; Deutsche Gesellschaft für Gynäkologie und Geburtshilfe. Vorstellungen der DGGG zur wissenschaftlichen Weiterentwicklung und Struktur des Faches Gynäkologie und Geburtshilfe an den deutschen Universitäten. Geburtsh Frauenheilk 2012; 72: 777-779 